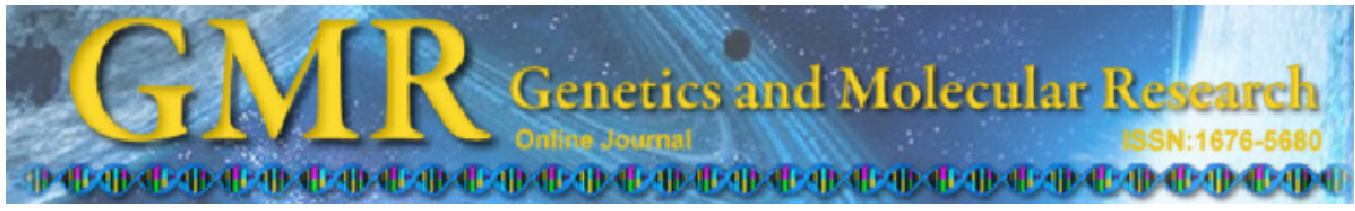

\title{
Role of CASP-10 gene polymorphisms in cancer susceptibility: a HuGE review and meta-analysis
}

\author{
S. Yan, Y.Z. Li, J.W. Zhu, C.L. Liu, P. Wang and Y.L. Liu \\ Department of Urological Surgery, Fourth Affiliated Hospital, \\ China Medical University, Shenyang, Liaoning, China \\ Corresponding author: Y.L. Liu \\ E-mail: cmu4h_lyl@126.com \\ Genet. Mol. Res. 11 (4): 3998-4007 (2012) \\ Received May 24, 2012 \\ Accepted October 11, 2012 \\ Published November 26, 2012 \\ DOI http://dx.doi.org/10.4238/2012.November.26.1
}

\begin{abstract}
We investigated a possible association between $C A S P-10$ gene polymorphisms and susceptibility to cancer through a meta-analysis. Eight studies with a total of 29,936 cancer cases and 34,041 healthy controls were included. Meta-analysis results showed that the rs $13006529 * \mathrm{~T}$ carrier was significantly associated with increased cancer risk $(\mathrm{OR}=1.17,95 \% \mathrm{CI}=1.01-1.36, \mathrm{P}=0.03)$. However, rs3900115 and rs13010627 showed no association with cancer susceptibility (all $\mathrm{P}>0.05$ ). In the subgroup analysis by cancer type, we found that the rs $13006529 * \mathrm{~T}$ carrier was a risk factor for breast cancer $(\mathrm{OR}=1.17,95 \% \mathrm{CI}=1.01-1.36, \mathrm{P}=0.03)$. Similarly, no association was found between $C A S P-10$ polymorphisms and susceptibility to lymphoma, myeloma, melanoma, or lung cancer (all $\mathrm{P}>0.05)$. This meta-analysis suggests that the rs $13006529 * \mathrm{~T}$ carrier in the $C A S P-10$ gene might be a risk factor for cancer susceptibility, especially for breast cancer.
\end{abstract}

Key words: $C A S P-10$; Genetic polymorphisms; Cancer; Susceptibility; Meta-analysis 


\section{INTRODUCTION}

Apoptosis is a particular type of programmed cell death that commonly occurs in the developing embryo, normal healthy adult tissues, and many pathological settings (Alison and Sarraf, 1992). The morphological features of apoptosis include changes in plasma membrane asymmetry and attachment, cytoplasm condensation, and nucleus and internucleosomal DNA cleavage (Doonan and Cotter, 2008). Dysregulation of apoptosis, resulting in too little or excessive cell death is implicated in the pathogenesis of stroke, myocardial infarction, neurodegenerative diseases, cancer, and autoimmune disorders (Rupinder et al., 2007). Among the 14 mammalian caspases identified thus far, only caspase-10 shares homologous death-effector domains with caspase-8, suggesting that caspase-10 may also interact with death receptors (Wang et al., 2001; Ghavami et al., 2009). Dysregulation of apoptosis is one of the hallmarks of cancers (Kim et al., 2009). Caspase-10 is an initiation-phase caspase, and somatic mutations of the CASP-10 gene have been reported in many cancers (Oh et al., 2010). Park et al. (2002) confirmed that somatic alterations of the CASP-10 gene might contribute to pathogenesis in a subset of gastric cancers through the loss of their apoptotic function. Kim et al. (2009) also found that $C A S P-10$ mutation might contribute to the pathogenesis of acute leukemias and multiple myelomas. Moreover, Shin et al. (2002) analyzed the entire coding region and all splice sites of the $C A S P-10$ gene to detect somatic mutations in 117 cases of human non-Hodgkin's lymphoma. They suggested that apoptotic dysregulation due to CASP-10 mutation may mediate lymphomatogenesis. However, Oh et al. (2010) found that mutation of $C A S P-10$ is rare in colon, breast, lung, and hepatocellular carcinomas. To address the inconsistencies in these studies and assess the association between CASP-10 gene polymorphisms and cancer susceptibility, we performed a Human Genome Epidemiology (HuGE) review and meta-analysis based on published case-control studies.

\section{MATERIAL AND METHODS}

\section{Literature search}

We extensively searched PubMed, Cochrane Library, Embase, Web of Science, Springerlink, CNKI, and CBM databases (last search was updated on May 10, 2012) to identify relevant studies. Search terms included ["Caspase-10" or "Caspase-10" or "Caspase 10" (Mesh)] and ["SNPs" or "SNP" or "polymorphism" or "polymorphism, genetic" (Mesh)] and ["cancer" or "tumor" or "Neoplasms" (Mesh)]. References in eligible studies or textbooks were also reviewed.

\section{Inclusion and exclusion criteria}

The included studies had to meet the following criteria: the type of study should be a case-control study; the study must be focused on associations between CASP-10 gene polymorphisms and cancer susceptibility; all patients must have the diagnosis of malignant tumor confirmed by pathological examination of the surgical specimen; the frequencies of alleles or genotypes in case and control groups should be capable of extraction, 
and the publication should be in English or Chinese. Studies were excluded when they were not case-control studies of $C A S P$ - 10 gene polymorphisms, and cancer risk; if they were based on incomplete data; if useless or overlapping data were reported, or if it were meta-analyses, letters, reviews, or editorial articles.

\section{Data extraction}

Using a standardized form, data from published studies were extracted independently by two reviewers (Yan S and Li YZ) to collect information including: first author, year of publication, country, language, ethnicity, study design, diagnostic criteria, source of cases and controls, number of cases and controls, sample, cancer types, genotype methods, allele or genotype frequency, and evidence of Hardy-Weinberg equilibrium (HWE) in controls. In cases of conflicting evaluations, an agreement was reached following a discussion with a third reviewer (Liu YL).

\section{Quality assessment of the studies included}

Two reviewers (Zhu JW and Liu CL) independently assessed the quality of the papers according to modified STROBE quality score systems (von Elm et al., 2007; Zhang et al., 2011). Forty quality appraisal items were used in this meta-analysis, with scores ranging from 0 to 40 . Scores of $0-20,20-30$, and 30-40 were defined as low, moderate, and high quality, respectively. Disagreement was resolved by discussion with a third reviewer (Liu YL).

\section{Statistical analysis}

The odds ratio (OR) and $95 \%$ confidence interval $(95 \% \mathrm{CI})$ were calculated in Review Manager Version 5.1.6 (provided by the Cochrane Collaboration, available at: http://ims. cochrane.org/revman/download) and STATA version 12.0 (Stata Corp, College Station, TX, USA). Between-study variations and heterogeneities were estimated using Cochran's Q-statistic (Higgins and Thompson, 2002; Zintzaras and Ioannidis, 2005) $(\mathrm{P} \leq 0.05$ was considered to represent statistically significant heterogeneity). We also quantified the effect of heterogeneity by using the $\mathrm{I}^{2}$ test. $\mathrm{I}^{2}$ ranges between 0 and $100 \%$ and represents the proportion of interstudy variability that can be attributed to heterogeneity rather than chance. $I^{2}$ values of 25,50 , and $75 \%$ were defined as low, moderate, and high estimates, respectively. When a significant Q-test $(\mathrm{P}<0.10)$ or $\mathrm{I}^{2}>50 \%$ indicated heterogeneity across studies, the random effects model was generated for meta-analysis, or the fixed effects model was used. We tested whether the genotype frequencies of controls were in HWE using the $\chi^{2}$ test. Subgroup analysis based on country was used to explore and explain the diversity of results from the selected studies. Sensitivity analysis was mainly performed by sequential omission of individual studies. Publication bias was investigated by the Begger funnel plot, and funnel plot asymmetry was assessed by the Egger linear regression test (Peters et al., 2006); statistical significance was indicated when the $\mathrm{P}$ value of the Egger test was $<0.05$. All $\mathrm{P}$ values were two-sided. To ensure reliability and accuracy, two reviewers (Yan S and Li YZ) independently populated the data in the statistics software programs and obtained the same results. 


\section{RESULTS}

\section{The characteristics of the studies included}

According to the inclusion criteria, 8 studies (MacPherson et al., 2004; Ye, 2004; Frank et al., 2006; Lan et al., 2007; Hosgood et al., 2008; Li et al., 2008; Gaudet et al., 2009; Ulybina et al., 2009) were included and 97 were excluded. A flow chart of the study selection process is shown in Figure 1 . The total number of cancer cases and healthy controls were 29,936 and 34,041 in these 8 case-control studies, which evaluated the relationship between CASP-10 polymorphisms and cancer susceptibility. Publication year ranged from 2004 to 2009. All patients fulfilled the diagnosis criteria of malignant tumor confirmed by pathological examination of a surgical specimen. The source of controls was based on a healthy population. Three polymorphisms in the CASP-10 gene were addressed, including rs13006529 (I522L) A $>$ T in exon 10, rs13010627 (V410I) G>A in exon 9 and rs3900115 (A2823G) A $>$ G in exon 3. Overall, there were 3 breast studies, 2 lymphoma studies, and 3 others including myeloma, melanoma, and lung cancer. Seven of these studies were conducted in a Caucasian population, 1 was in an Asian population. HWE was conducted for the controls in every study. All studies showed HWE except Ulybina et al. $(\mathrm{P}<0.05)$. All quality scores were $>20$ (moderate-high quality). The characteristics and methodological quality of the studies are summarized in Table 1. The genotype distributions of CASP-10 gene polymorphisms in case and control groups are presented in Table 2.

\section{Association between $C A S P-10$ polymorphisms and cancer risk}

A summary of the meta-analysis findings of the association between CASP-10 gene polymorphisms and cancer risk is provided in Table 3. The meta-analysis result showed that the rs $13006529^{*} \mathrm{~T}$ carrier was significantly associated with increased cancer risk $(\mathrm{OR}=1.17$,

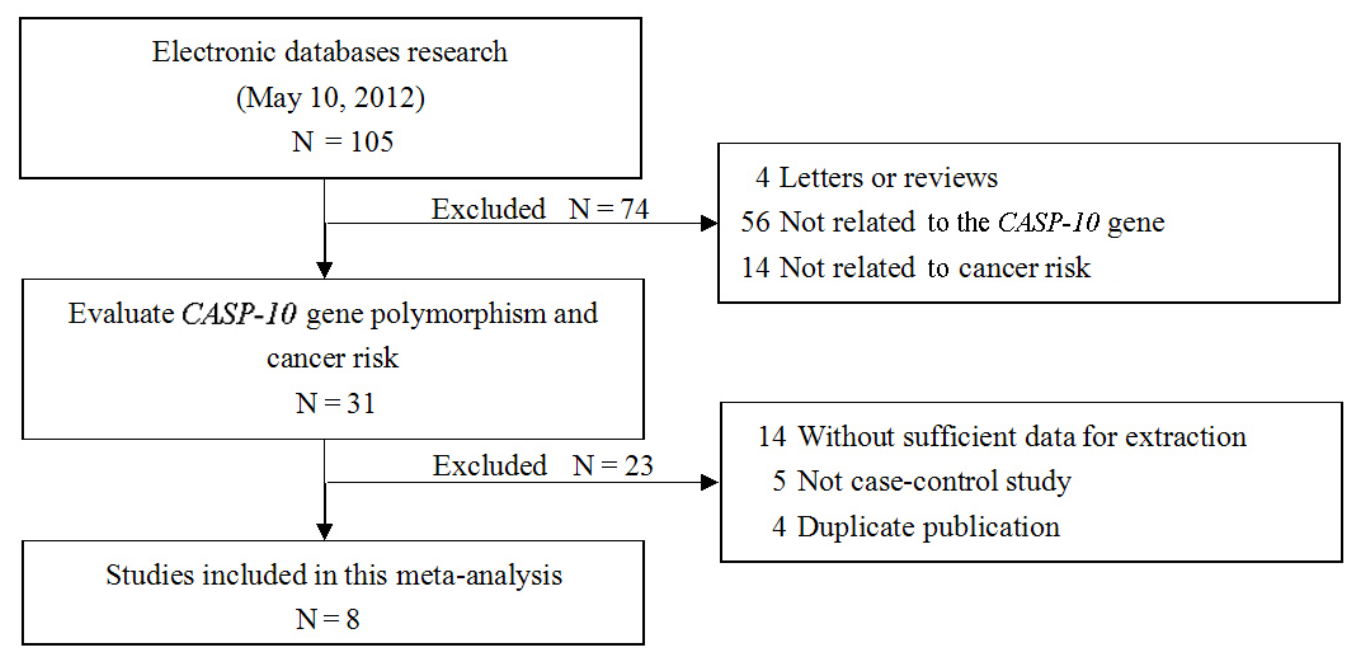

Figure 1. Flow chart of the study selection procedure. 
S. Yan et al.

4002

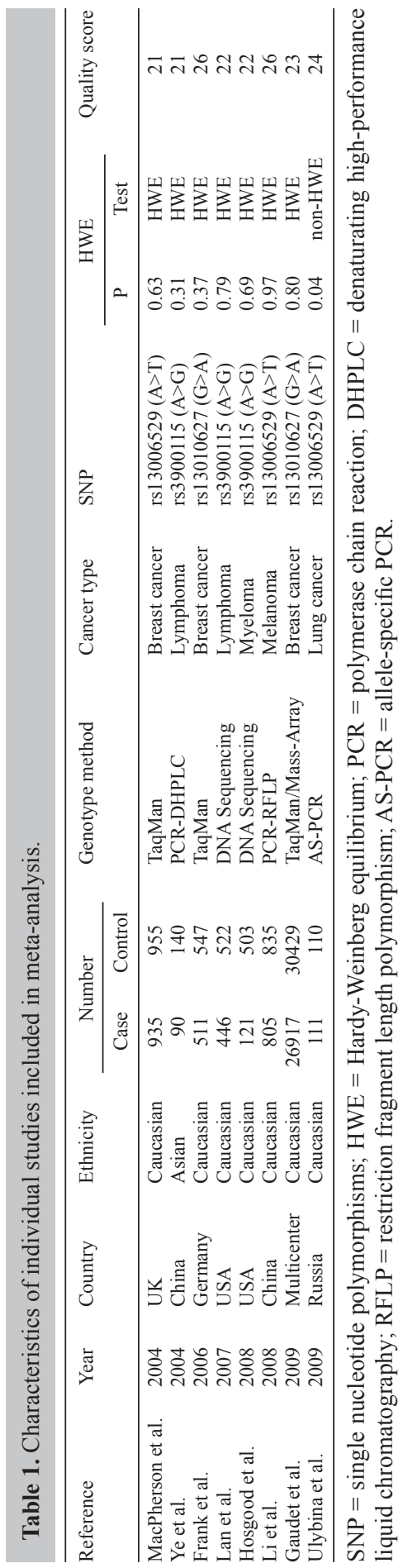

Genetics and Molecular Research 11 (4): 3998-4007 (2012)

CFUNPEC-RP www.funpecrp.com.br 


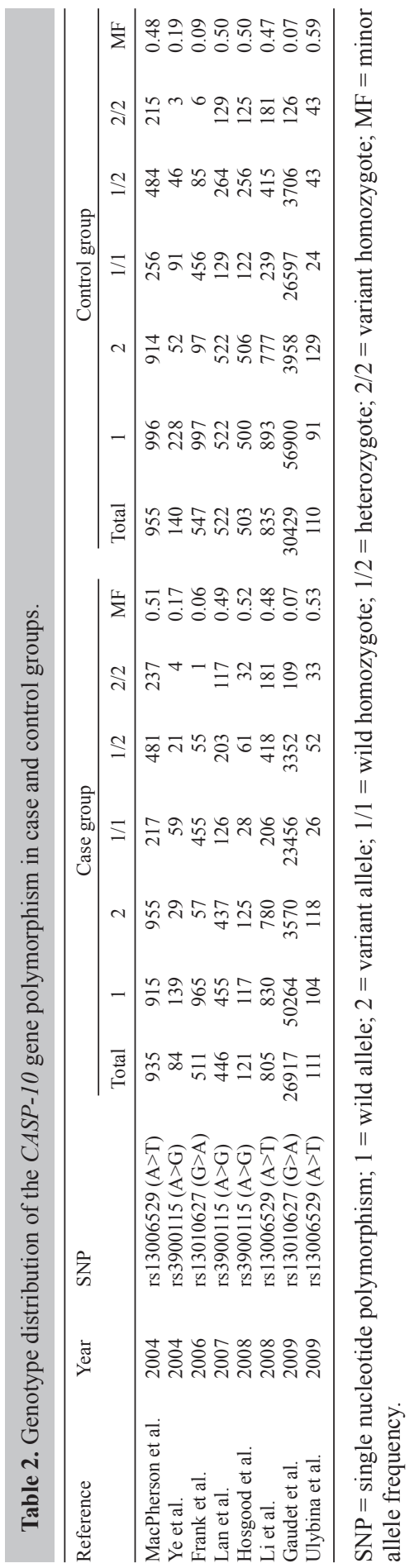


$95 \% \mathrm{CI}=1.01-1.36, \mathrm{P}=0.03)($ Figure 2$)$. However, $\mathrm{rs} 3900115$ and $\mathrm{rs} 13010627$ showed no association with cancer susceptibility (all $\mathrm{P}>0.05$ ). In the subgroup analysis by cancer type, we found that the rs $13006529^{*} \mathrm{~T}$ carrier was a risk factor for breast cancer $(\mathrm{OR}=1.17,95 \% \mathrm{CI}$ $=1.01-1.36, \mathrm{P}=0.03)$. Similarly, no association was found between $C A S P-10$ polymorphisms and susceptibility to lymphoma, myeloma, melanoma, or lung cancer (all $\mathrm{P}>0.05$ ). The significance of pooled OR in all individual analyses was not influenced excessively by omitting any single study and non-HWE studies (Ulybina et al., 2009).

Table 3. Meta-analysis of the association between $C A S P-10$ gene polymorphisms and cancer risk.

\begin{tabular}{|c|c|c|c|c|c|c|c|}
\hline \multirow[t]{2}{*}{ Polymorphisms } & \multirow[t]{2}{*}{ Cancer $(\mathrm{n} / \mathrm{N})$} & \multirow[t]{2}{*}{ Control $(\mathrm{n} / \mathrm{N})$} & \multirow[t]{2}{*}{ OR $(95 \% \mathrm{CI})$} & \multirow[t]{2}{*}{$\mathrm{P}$} & \multicolumn{2}{|c|}{ Heterogeneity } & \multirow[t]{2}{*}{ Effect model } \\
\hline & & & & & $\mathrm{P}$ & $\mathrm{I}^{2}$ & \\
\hline \multicolumn{8}{|c|}{ rs13006529 (A>T) } \\
\hline $\mathrm{T}$ allele & $1853 / 3702$ & $1820 / 3800$ & $1.09(1.00,1.19)$ & 0.06 & 0.22 & $34 \%$ & \multirow[t]{4}{*}{ Fixed } \\
\hline $\mathrm{AT}+\mathrm{TT}$ & $1402 / 1851$ & $1381 / 1900$ & $1.17(1.01,1.36)$ & 0.03 & 0.70 & $0 \%$ & \\
\hline $\mathrm{TT}$ & $451 / 1851$ & $439 / 1900$ & $1.07(0.92,1.24)$ & 0.38 & 0.17 & $44 \%$ & \\
\hline $\mathrm{AT}$ & $951 / 1851$ & $942 / 1900$ & $1.08(0.95,1.22)$ & 0.27 & 0.59 & $0 \%$ & \\
\hline \multicolumn{8}{|l|}{$\operatorname{rs} 3900115(A>G)$} \\
\hline $\mathrm{G}$ allele & $591 / 1302$ & $1080 / 2330$ & $0.98(0.85,1.13)$ & 0.79 & 0.82 & $0 \%$ & \multirow[t]{4}{*}{ Fixed } \\
\hline $\mathrm{AG}+\mathrm{GG}$ & $438 / 651$ & $823 / 1165$ & $0.87(0.70,1.09)$ & 0.24 & 0.64 & $0 \%$ & \\
\hline GG & $153 / 651$ & $257 / 1165$ & $1.10(0.87,1.41)$ & 0.42 & 0.64 & $0 \%$ & \\
\hline $\mathrm{AG}$ & $285 / 651$ & $566 / 1165$ & $0.84(0.69,1.03)$ & 0.09 & 0.58 & $0 \%$ & \\
\hline \multicolumn{8}{|c|}{$\operatorname{rs} 13010627(\mathrm{G}>\mathrm{A})$} \\
\hline A allele & $3627 / 54856$ & $4055 / 61952$ & $0.81(0.49,1.34)$ & 0.41 & $<0.01$ & $89 \%$ & \multirow[t]{4}{*}{ Random } \\
\hline $\mathrm{GA}+\mathrm{AA}$ & $3517 / 27428$ & $3923 / 30976$ & $0.82(0.50,1.34)$ & 0.43 & $<0.01$ & $87 \%$ & \\
\hline $\mathrm{AA}$ & $110 / 27428$ & $132 / 30976$ & $0.58(0.12,2.73)$ & 0.49 & 0.12 & $60 \%$ & \\
\hline GA & $3407 / 27428$ & $3791 / 30976$ & $0.85(0.55,1.31)$ & 0.47 & 0.02 & $83 \%$ & \\
\hline
\end{tabular}

$\mathrm{OR}=$ odds ratio $; 95 \% \mathrm{CI}=95 \%$ confidence interval.

\begin{tabular}{|c|c|c|c|c|c|c|c|c|c|c|}
\hline Study or Subgroup & $\begin{array}{r}\text { Case } \\
\text { Events }\end{array}$ & Total & $\begin{array}{l}\text { Contr } \\
\text { Events }\end{array}$ & $\begin{array}{l}\text { ol } \\
\text { Total }\end{array}$ & Weight & $\begin{array}{l}\text { Odds ratio } \\
\text { M-H, Fixed, } 95 \% \mathrm{Cl}\end{array}$ & & $\begin{array}{r}\text { Odds } \\
\text { M-H, Fixe }\end{array}$ & $\begin{array}{l}s \text { ratio } \\
\text { ed, } 95 \% \mathrm{Cl}\end{array}$ & \\
\hline MacPherson et al., 2004 & 718 & 935 & 699 & 955 & $48.6 \%$ & $1.21[0.98,1.49]$ & & & & \\
\hline Li et al., 2008 & 599 & 805 & 596 & 835 & $45.3 \%$ & $1.17[0.94,1.45]$ & & & & \\
\hline Ulybina et al., 2009 & 85 & 111 & 86 & 110 & $6.1 \%$ & $0.91[0.49,1.71]$ & & & & \\
\hline Total $(95 \% \mathrm{Cl})$ & & 1851 & & 1900 & $100.0 \%$ & $1.17[1.01,1.36]$ & & & & \\
\hline Total events & 1402 & & 1381 & & & & & & & \\
\hline \multicolumn{7}{|c|}{$\begin{array}{l}\text { Heterogeneity: } \mathrm{Chi}^{2}=0.71 \text {, d.f. }=2(P=0.70) ; I^{2}=0 \% \\
\text { Test for overall effect: } Z=2.13(P=0.03)\end{array}$} & $\begin{array}{l}0.10 .2 \\
\text { Favour }\end{array}$ & $\begin{array}{c}0.5 \\
\text { rs control }\end{array}$ & 12 & $\begin{array}{cc}5 & 10 \\
5 a s e & \end{array}$ \\
\hline
\end{tabular}

Figure 2. Association between the $\mathrm{rs} 13006529^{*} \mathrm{~T}$ carrier and cancer susceptibility. M-H. = Mantel-Haenszel estimator; $95 \% \mathrm{CI}=95 \%$ confidence interval; d.f. $=$ degrees of freedom.

\section{Publication bias}

Publication bias of the literatures was assessed based on the rs $13006529 * \mathrm{~T}$ carrier by the Begger funnel plot and the Egger linear regression test. The Egger linear regression test was used to measure the asymmetry of the funnel plot. All graphical funnel plots appeared to be symmetrical (Figure 3). The Egger test also showed no statistical significance for all evaluations of publication bias $(\mathrm{P}>0.05)$. Findings of the Egger publication bias test are shown in Table 4. 

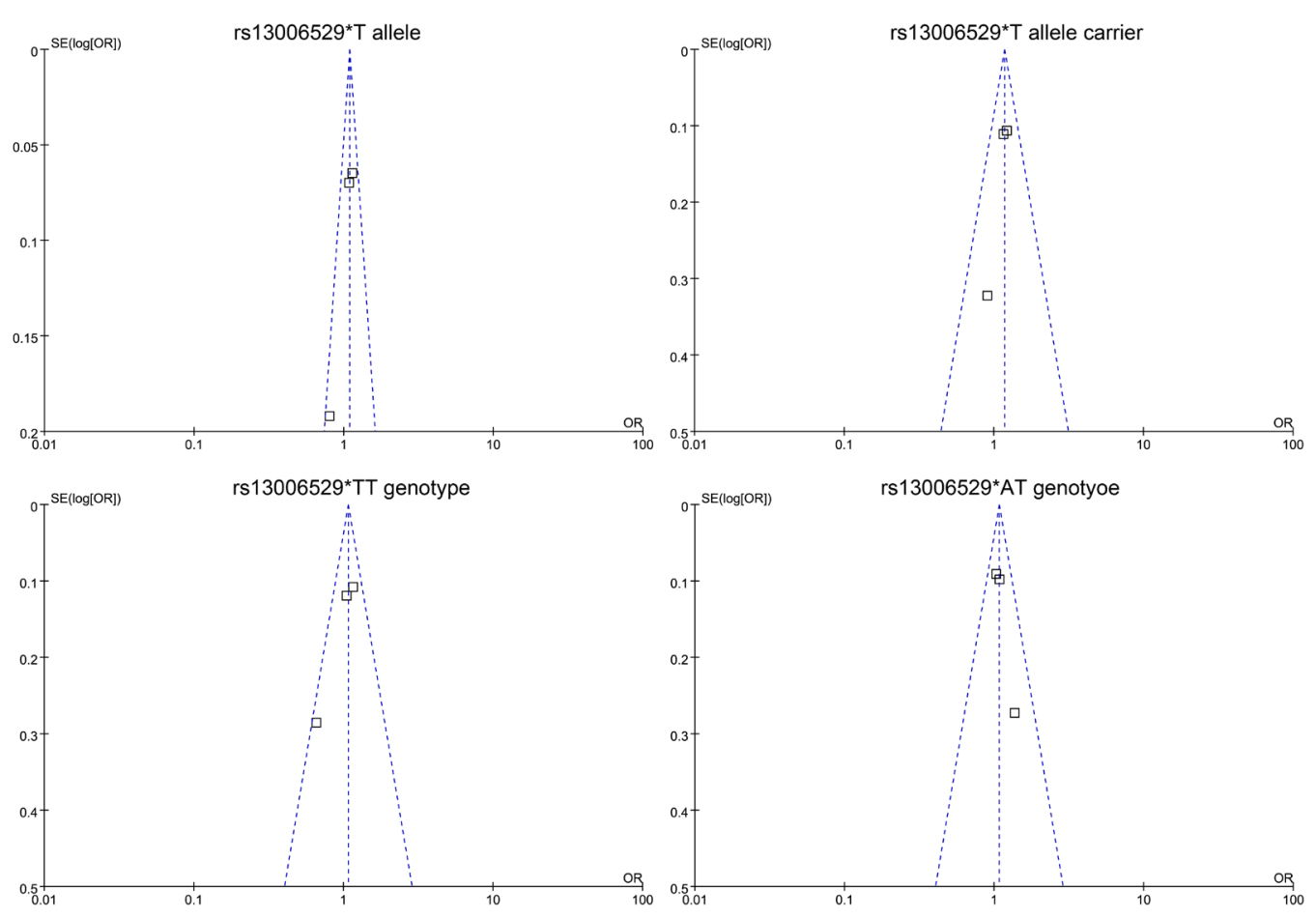

Figure 3. Begger funnel plot of publication bias based on rs 13006529. $\mathrm{SE}=$ standard error; $\mathrm{OR}=$ odds ratio.

Table 4. Evaluation of publication bias based on rs 13006529 by the Egger linear regression test.
\begin{tabular}{lccccr}
\hline Comparison & Coefficient & SE & $t$ & P & $95 \%$ CI \\
\hline T allele & -2.680 & 0.643 & 0.643 & 0.150 & $(-10.845,5.485)$ \\
AT + TT & -1.262 & 0.327 & -3.860 & 0.161 & $(-5.416,2.892)$ \\
TT & -3.135 & 0.792 & -3.960 & 0.158 & $(-13.198,6.929)$ \\
AT & 1.507 & 0.565 & 2.660 & 0.229 & $(-5.678,8.692)$ \\
\hline SE = standard error; $95 \%$ CI $=95 \%$ confidence interval.
\end{tabular}

\section{DISCUSSION}

Caspases mediate highly specific proteolytic cleavage events in dying cells, which collectively manifest the apoptotic phenotype. The key and central role that caspases play in a biochemical cell-suicide pathway has been conserved throughout the evolution of multicellular eukaryotes (Nicholson and Thornberry, 1997). Activation of caspases is of fundamental importance in cell death commitment; thus, substantial efforts have been devoted to understand the mechanisms that underlie this process (Kumar, 2004). The proteolytic activities of the caspases initiate and augment the apoptotic response by maintaining enzymatic cascade in a committed program (Niles et al., 2008). Activated caspases degrade important structural protein elements within cells and RNA splicing or DNA repair-associated proteins (Boatright 
and Salvesen, 2003). However, excessive or failed apoptosis is a prominent morphological feature of several human diseases (Nicholson, 1996). These can be divided into disorders of excessive apoptosis (such as neurodegenerative diseases or ischemic damage) and those where insufficient apoptosis occurs (such as autoimmune syndromes, cancers, and sustained pathogenic infections). Caspase 10 is a key regulator of apoptosis or programmed cell death and shares similar functions with caspase- 8 , as an essential defense mechanism against hyperproliferation and malignancy (Ghavami et al., 2009).

Recent studies have established that $C A S P-10$ variants may dysregulate apoptosis and thus lead to carcinogenesis. A systematic review of the association of CASP-10 with cancer risk is statistically more powerful than any single study. In this meta-analysis, including 29,936 cancer cases and 34,041 healthy controls from 8 independent studies, we examined 3 SNPs in the CASP-10 gene, including rs13006529 (I522L) $\mathrm{A}>\mathrm{T}$ in exon 10, rs13010627 (V410I) $\mathrm{G}>\mathrm{A}$ in exon 9, and rs3900115 (A2823G) $\mathrm{A}>\mathrm{G}$ in exon 3. We demonstrated that the $\mathrm{T}$ allele carrier (AT + TT) of rs 13006529 was significantly associated with cancer risk after adjustment for multiple testing. However, the T allele, TT and AT genotypes of rs13006529 showed no association with cancer risk. Pooled analysis has revealed no association between rs3900115 and rs13010627 with cancer susceptibility. Subgroup analysis showed that the rs13006529 T allele is a risk factor for breast cancer. Nevertheless, no association was found between CASP10 gene polymorphisms and susceptibility to lymphoma, myeloma, melanoma, or lung cancer. Sensitivity analysis was performed by omitting any single study and non-HWE studies: no influence was found. Many limitations of this meta-analysis should be addressed. First, the relevant research articles are few and the sample size of this meta-analysis was not large. In addition, some relevant studies could not be included due to incomplete raw data. Third, we were not able to address the sources of heterogeneity among all studies. Fourth, although all cases and controls were well defined with similar inclusion criteria, there may be factors that were not taken into account and that may have influenced our results. Most important, our meta-analysis was based on unadjusted OR estimates because not all publications presented adjusted ORs and when they did, the ORs were not adjusted by the same potential confounders, such as ethnicity, gender, geographic distribution, etc. Given these results, additional investigation in these areas is needed, and our conclusions should be interpreted cautiously.

In conclusion, this meta-analysis of 8 case-control studies demonstrated that CASP10 polymorphisms are associated with the pathogenesis of various cancer. The rs $13006529 \mathrm{~T}$ allele (AT + TT) might increase the risk of cancer, especially breast cancer. Since only a few studies are available in this field and evidence remains limited, we emphasize the need to conduct large studies with adequate methodological quality, and proper control of confounding factors in order to obtain valid results.

\section{ACKNOWLEDGMENTS}

We would like to thank J.L. Liu (MedChina Medical Information Service Co., Ltd.) for his valuable contribution and kind review of the manuscript.

\section{REFERENCES}

Alison MR and Sarraf CE (1992). Apoptosis: a gene-directed programme of cell death. J. R. Coll. Physicians Lond. 26: 25-35. 
Boatright KM and Salvesen GS (2003). Mechanisms of caspase activation. Curr. Opin. Cell Biol. 15: 725-731.

Doonan F and Cotter TG (2008). Morphological assessment of apoptosis. Methods 44: 200-204.

Frank B, Hemminki K, Wappenschmidt B, Meindl A, et al. (2006). Association of the CASP10 V410I variant with reduced familial breast cancer risk and interaction with the CASP8 D302H variant. Carcinogenesis 27: 606-609.

Gaudet MM, Milne RL, Cox A, Camp NJ, et al. (2009). Five polymorphisms and breast cancer risk: results from the Breast Cancer Association Consortium. Cancer Epidemiol. Biomarkers Prev. 18: 1610-1616.

Ghavami S, Hashemi M, Ande SR, Yeganeh B, et al. (2009). Apoptosis and cancer: mutations within caspase genes. $J$. Med. Genet. 46: 497-510.

Higgins JP and Thompson SG (2002). Quantifying heterogeneity in a meta-analysis. Stat. Med. 21: 1539-1558.

Hosgood HD, III, Baris D, Zhang Y, Zhu Y, et al. (2008). Caspase polymorphisms and genetic susceptibility to multiple myeloma. Hematol. Oncol. 26: 148-151.

Kim MS, Oh JE, Min CK, Lee S, et al. (2009). Mutational analysis of CASP10 gene in acute leukaemias and multiple myelomas. Pathology 41: 484-487.

Kumar S (2004). Measurement of caspase activity in cells undergoing apoptosis. Methods Mol. Biol. 282: 19-30.

Lan Q, Zheng T, Chanock S, Zhang Y, et al. (2007). Genetic variants in caspase genes and susceptibility to non-Hodgkin lymphoma. Carcinogenesis 28: 823-827.

Li C, Zhao H, Hu Z, Liu Z, et al. (2008). Genetic variants and haplotypes of the caspase-8 and caspase-10 genes contribute to susceptibility to cutaneous melanoma. Hum. Mutat. 29: 1443-1451.

MacPherson G, Healey CS, Teare MD, Balasubramanian SP, et al. (2004). Association of a common variant of the CASP8 gene with reduced risk of breast cancer. J. Natl. Cancer Inst. 96: 1866-1869.

Nicholson DW (1996). ICE/CED3-like proteases as therapeutic targets for the control of inappropriate apoptosis. Nat. Biotechnol. 14: 297-301.

Nicholson DW and Thornberry NA (1997). Caspases: killer proteases. Trends Biochem. Sci. 22: 299-306.

Niles AL, Moravec RA and Riss TL (2008). Caspase activity assays. Methods Mol. Biol. 414: 137-150.

Oh JE, Kim MS, Ahn CH, Kim SS, et al. (2010). Mutational analysis of CASP10 gene in colon, breast, lung and hepatocellular carcinomas. Pathology 42: 73-76.

Park WS, Lee JH, Shin MS, Park JY, et al. (2002). Inactivating mutations of the caspase-10 gene in gastric cancer. Oncogene 21: 2919-2925.

Peters JL, Sutton AJ, Jones DR, Abrams KR, et al. (2006). Comparison of two methods to detect publication bias in metaanalysis. JAMA 295: 676-680.

Rupinder SK, Gurpreet AK and Manjeet S (2007). Cell suicide and caspases. Vascul. Pharmacol. 46: 383-393.

Shin MS, Kim HS, Kang CS, Park WS, et al. (2002). Inactivating mutations of CASP10 gene in non-Hodgkin lymphomas. Blood 99: 4094-4099.

Ulybina YM, Kuligina ES, Mitiushkina NV, Rozanov ME, et al. (2009). Coding polymorphisms in Casp5, Casp8 and DR4 genes may play a role in predisposition to lung cancer. Cancer Lett. 278: 183-191.

von Elm E, Altman DG, Egger M, Pocock SJ, et al. (2007). The Strengthening the Reporting of Observational Studies in Epidemiology (STROBE) statement: guidelines for reporting observational studies. Epidemiology 18: 800-804.

Wang J, Chun HJ, Wong W, Spencer DM, et al. (2001). Caspase-10 is an initiator caspase in death receptor signaling. Proc. Natl. Acad. Sci. U. S. A. 98: 13884-13888.

Ye YF (2004). Polymorphisms of Caspase-8, -10 Genes and Their Relationship with Pathogenesis of Non-Hodgkin lymphoma. Master's thesis, Zhejiang University School of Medicine, Zhejiang.

Zhang L, Liu JL, Zhang YJ and Wang H (2011). Association between HLA-B*27 polymorphisms and ankylosing spondylitis in Han populations: a meta-analysis. Clin. Exp. Rheumatol. 29: 285-292.

Zintzaras E and Ioannidis JP (2005). Heterogeneity testing in meta-analysis of genome searches. Genet. Epidemiol. 28: 123-137. 